International Review of Research in Open and Distributed Learning Volume 22, Number 3

August - 2021

\title{
What Motivates Students About Open Pedagogy? Motivational Regulation Through the Lens of Self- Determination Theory
}

Eric Werth and Katherine Williams

Office of Professional Development, University of Pikeville

\begin{abstract}
Open pedagogy is growing in popularity as an instructional method to decentralize classroom power dynamics, engage students, and provide greater meaning to student work. To investigate the impact of open pedagogy on motivation, interviews were conducted with first-year college students at a four-year liberal arts college after completing a semester-long project based on this pedagogical approach. Student responses were assessed using self-determination theory as a theoretical framework, particularly in relation to the motivation regulatory styles displayed by research participants. Results indicate that students experienced various forms of extrinsic motivation during the project based on open pedagogy, with autonomous forms of regulation being more prevalent than controlled regulation. Interview data also suggest that agency plays a role in mediating the internalization of student motivation. Based on these findings, suggestions are provided to the design of assignments in general and open pedagogy specifically to enhance development of autonomous forms of motivation.
\end{abstract}

Keywords: OER-enabled pedagogy, open pedagogy, motivation, self-determination theory, non-disposable assignment 


\section{Introduction}

During the first year of college, students face financial, social, and academic stress (Mudhovozi, 2012; Pillay \& Ngcobo, 2010). These pressures can be particularly strong in underrepresented and traditionally at-risk populations such as minorities and first-generation students (Alessi et al., 2017; Jenkins et al., 2020; Lightweis, 2014; Pulliam \& Gonzalez, 2018). Engaging and motivating students can helps address student skill gaps, provide positive psychological benefits, and potentially reduce attrition (Dewey, 2018; Hanover Research, 2014; Reynolds \& Weigand, 2010; Reeve, 2006; Robbins et al., 2004; Roberts \& Styron, 2010). Tragically, the gaps we have been trying to eliminate will likely widen due to COVID-19 (Hess, 2020; Polikoff et al., 2020).

Open pedagogy engages students as cocreators of knowledge while making education more meaningful, participatory, and democratic (DeRosa \& Robison, 2017; Hegarty, 2015; Wiley et al., 2017). A key element of open pedagogy is student creation of non-disposable/renewable assignments (NDAs). NDAs are those that provide value to others, are available to wider audiences, and may be licensed openly (Wiley \& Hilton, 2018). Using NDAs may allow learners to attribute greater value to their efforts (Al Abri \& Dabbagh, 2019; Allan et al., 2018; Farzan \& Kraut, 2013; Hilton et al., 2019; Jhangiani, 2017; Sheu, 2020). Evidence suggests that this approach has the potential to positively impact student skill, achievement, and engagement (Hilton et al., 2019; Marsh, 2018; Sheu, 2020; Wiley et al., 2017).

Although mounting research substantiates the impact of open pedagogy, existing studies are largely quantitative or theoretical. Relatively few have used a qualitative approach. While many aspects of open pedagogy would benefit from investigation, motivation has been described as an area where research is needed (Baran \& AlZoubi, 2020).

This article details interviews of students who participated in a project based on open pedagogy. The purpose of the study, conducted with first-year students, is to fill gaps in literature related to the types of motivation students experience with this approach. Although there are various models for motivation, this research uses self-determination theory, which allows for the examination of intrinsic versus extrinsic motivation and manifestations of extrinsic motivation based on the degree to which an individual internalizes regulatory behaviors (Deci \& Ryan, 2008). Actions that were once externally motivated, common in education, may become internally regulated by fostering the basic psychological needs of competency, autonomy, and relatedness (Deci \& Ryan, 2008). In turn, intrinsic motivation impacts students' academic and psychological health (Froiland et al., 2012; Reeve, 2012; Vansteenkiste et al., 2018).

The theoretical frameworks guiding this study were open pedagogy and self-determination theory. Results provide us with insight into how various elements of open pedagogy motivate students, as well as ways educators may structure such activities to make them most beneficial. As various forms of extrinsic motivation have been associated with different student outcomes (Howard et al., 2020; Wang et al., 2020), results also provide an opportunity to construct learning environments that enhance student academic performance, foster transfer and maintenance of skills, and promote student psychosocial well-being. 


\section{Reflexivity}

Reflexivity is the understanding that we are not neutral observers as researchers (Creswell, 2007). We wish to be transparent in our identities as it impacts our interconnectedness to participants, the methodological approach, and interpretation of results. We recognize we wield power as both researchers and practitioners and desire to shift power dynamics of traditional education. Doing so disrupts hegemonic approaches common in education and give voice to the marginalized.

\section{Literature Review}

\section{Open Pedagogy and OER-Enabled Pedagogy}

Open pedagogy is an evolving concept with the goal of making education more meaningful, participatory, and engaging (Cronin \& MacLaren, 2018; DeRosa \& Robison, 2017; Hegarty, 2015; Lane, 2009; Wiley et al., 2017). Distributed learning, participatory technology, and collaborative approaches are central to open pedagogy (Hegarty, 2015; Inamorato dos Santos et al., 2016). This approach aligns with critical pedagogy and social justice in education (Bali et al., 2020; DeRosa \& Robison, 2017).

Although frequently discussed, open pedagogy has proven difficult to define. The variety of conceptualizations makes communication between practitioners or researchers difficult. Wiley and Hilton (2018) propose the term OER-enabled pedagogy to specifically refer to practices that are only possible within the $5 \mathrm{R}$ permissions of OER: retain, revise, remix, reuse, and redistribute (Wiley, n.d.). A project fitting this description must meet the following characteristics:

1. Students create new learning objects.

2. The work has value beyond the creator.

3. Students are invited to share work publicly.

4. Students may use open licensing in distributing works. (Wiley \& Hilton, 2018)

Open pedagogy may foster critical thinking skills, self-direction, and overall enjoyment of education (Dermody, 2019; Hegarty, 2015; Hilton et al., 2019; Tillinghast, 2020; Wiley et al., 2017).

\section{Non-Disposable Assignments}

NDAs are central to open pedagogy. As student work extends beyond the student-teacher relationship and potentially benefits others, NDAs are hypothesized to increase student engagement and motivation (Al Abri \& Dabbagh, 2019; Allan et al., 2018; Farzan \& Kraut, 2013; Hilton et al., 2019; Jhangiani, 2017; Seraphin et al., 2019; Sheu, 2020; Stommel, 2015; Wiley, 2013). Students acting as content creators has the added benefit of fostering learner agency and shifting the course structure to a more student-empowered, studentcentered experience (DeRosa \& Robison, 2017). 
There is evidence that NDAs positively impact students (Hilton et al., 2019; Marsh, 2018; Sheu, 2020; Wiley et al., 2017). Hilton et al. (2019) indicate that learners report mastery of academic content, skills in collaborative learning, critical thinking and problem solving, effective communication, and learning how to learn as benefits of Open Pedagogy. Sheu (2020) reported that when given a choice, the majority of students elected to complete an NDA over a disposable alternative.

\section{Motivation and Self-Determination Theory}

Motivation can be defined as an internal factor that elicits focused behavior toward a goal (Woolfolk, 2019). Common elements in motivational theories include the importance of competency, self-determination, and perceived meaning (Seifert, 2004). Generalizations may also be made as to effective instructional design, namely, the importance of building the following: (a) self-efficacy and competence, (b) control, (c) intrinsic and extrinsic motivation, (d) value, and (e) goals (Pintrich, 2003).

Self-determination theory (SDT) posits that three fundamental human needs drive motivation: competence, relatedness, and autonomy (Deci \& Ryan, 2000; Ryan \& Deci, 2000). SDT focuses not only on the amount and type of motivation one experiences but also how environment impacts motivation (Deci \& Ryan, 2008). It differentiates between autonomous and controlled motivation. Autonomous motivation may be either intrinsic or extrinsic and relates to behavior that is driven by an internalization of the value of the activity (Deci \& Ryan, 2008). Controlled motivation results from situations in which one is prompted by external pressures (Deci \& Ryan, 2008).

SDT states that different regulatory processes exist with motivation (Deci \& Ryan, 2000; Plant \& Ryan, 1985; Ryan, 1982; Ryan \& Deci, 2000). Extrinsic motivation includes four processes, differentiated by the level of integration of the behavior with internal values (see Table 1). Intrinsic motivation consists of a single regulatory style, characterized by an internal locus of control, participation in a behavior being volitional and for personal enjoyment/fulfillment, and complete integration of the behavior with the concept of self (Deci \& Ryan, 2000; Ryan \& Deci, 2000; Vansteenkiste et al., 2018).

\section{Table 1}

Intrinsic and Extrinsic Motivation Regulatory Processes

\begin{tabular}{|l|l|l|}
\hline Motivation & $\begin{array}{c}\text { Regulatory } \\
\text { process }\end{array}$ & \\
\hline Extrinsic & $\begin{array}{l}\text { External } \\
\text { regulation }\end{array}$ & Obtain a tangible reward or avoid punishment. \\
\cline { 2 - 3 } & $\begin{array}{l}\text { Introjected } \\
\text { regulation }\end{array}$ & $\begin{array}{l}\text { Consequences driving behavior are derived from the person themselves, } \\
\text { such as increasing self-worth or avoiding shame. }\end{array}$ \\
\cline { 2 - 4 } & Identified & Individuals see the personal value of a behavior. \\
\hline
\end{tabular}




\begin{tabular}{|l|l|l|}
\hline & regulation & \\
\cline { 2 - 3 } & $\begin{array}{l}\text { Integrated } \\
\text { regulation }\end{array}$ & $\begin{array}{l}\text { The value of a behavior has been integrated with existing values and } \\
\text { identity. Behaviors are done to attain some external outcome rather than } \\
\text { for enjoyment itself. }\end{array}$ \\
\hline Intrinsic & $\begin{array}{l}\text { Intrinsic } \\
\text { regulation }\end{array}$ & $\begin{array}{l}\text { Behaviors are engaged in voluntarily due to inherent enjoyment as } \\
\text { opposed to obtaining some external outcome. }\end{array}$ \\
\hline
\end{tabular}

Adapted from "Fostering personal meaning and self-relevance: A self-determination theory perspective on internalization” by M. Vansteenkiste et al., 2018, Journal of Experimental Education, 86. Copyright 2018 by Taylor \& Francis.

\section{Open Pedagogy and SDT in the Present Study}

In designing this project, care was taken to align student experience with literature on open pedagogy. Hegarty (2015) outlines eight attributes of open pedagogy, which we employed in relation to student experience:

1. Participatory technology: collaboration using the learning management system (LMS) and other tools for student communication;

2. People, openness, and trust: student agency, group work, and autonomy-supporting teaching;

3. Innovation and creativity: student research and freedom to create an artifact of their choosing;

4. Sharing ideas and resources: class discussions, student-led research;

5. Connected community: student connections made in and out of the classroom;

6. Learner generated: student-generated content and ideas throughout the project;

7. Reflective practice: weekly student reflective exercises; and

8. Peer review: draft review with rubric in the LMS.

Efforts were made to be open, transparent, collaborative, and social (Couros \& Hildebrandt, 2016) as well as learner driven, permitting students to help create the body of knowledge in which they were partaking (DeRosa \& Jhangiani, n.d.). The project fits the definition of OER-enabled pedagogy (Wiley \& Hilton, 2018), while the final artifact is a non-disposable assignment (Seraphin et al., 2019; Wiley \& Hilton, 2018). agencyFor clarity purposes, the project will be henceforth described as OER-enabled pedagogy. 


\section{Methods}

\section{Research Context}

This study was conducted at a liberal arts institution in the United States. All students attending this institution are required to take a first-year studies course. The course has been through iterations using various pedagogical approaches. It has also used a variety of readers, including faculty-designed course packs and traditional textbooks. Seeking to empower and motivate students, as well provide them with fundamental academic skills, the class was restructured around OER-enabled pedagogy. In this way, students could build academic skills, view work as having greater value than a grade, and create resources to replace paid text material in future classes.

The first-year studies course is traditionally taught face-to-face. Extensive use of the LMS, Canvas, allows students to collaborate outside of class and provides structure to the flow of the course. Considering that the institution has a large number of commuter students, flexible delivery options within the LMS was critical at all stages of the project. During class, students selected a topic they would have liked to have known more about when beginning college. Individually or in small groups, they developed an artifact of their choosing (e.g., video, infographic) to be included in an e-book. During the semester, students developed a research plan, submitted a proposal, gathered information about their topic, and conducted peer reviews. Those teaching the class's 18 sections were asked to maintain the structure of the common assignment including all assignment stages. The project then was intended to provide students autonomy, relatedness, and an opportunity to build competency.

To ensure ethical standards were upheld, the study was approved by the institution's institutional review board. This included maintaining student confidentiality in all stages of the research.

\section{Data Collection}

\section{Interviews and Coding Framework}

Semi-structured interviews were conducted with 16 students -7 male and 9 female. Seven students were identified because they responded to an invitation to all students to take part in research. To increase the sample size, students were randomly selected from course rosters and contacted for interviews. Nine additional participants were thus recruited. The average age of participants was 18.7 years. All students were offered a $\$ 10$ gift card for participation. Following 16 interviews, data collection ceased due to lack of new themes emerging. Verbatim transcripts were created from audio recordings and analyzed using the qualitative program Dedoose.

Researchers reviewed transcripts collaboratively taking an inductive and line-by-line approach (Charmaz, 2012; Skjott Linneberg \& Korsgaard, 2019). Open coding was followed by axial coding to develop categories/themes (Khandkar, n.d.). Following the description of motivation found in SDT, codes were categorized by the type of regulatory process they represented (see Table 2). 


\section{Table 2}

Primary and Secondary Codes Used in Transcript Evaluation

\begin{tabular}{|l|l|}
\hline \multicolumn{1}{|c|}{$\begin{array}{c}\text { Extrinsic motivation } \\
\text { processes }\end{array}$} & \multicolumn{1}{c|}{ Code categories } \\
\hline External regulation & Tangible rewarda; avoid a threat of punishment ${ }^{\mathrm{a}}$ \\
\hline Introjected regulation & Approach; avoidance ${ }^{\mathrm{b}}$ \\
\hline Identified regulation & $\begin{array}{l}\text { Pragmatic skill acquisition; aid in skill development of others; career } \\
\text { advancement; choice and personal interest motivate me }\end{array}$ \\
\hline Integrated regulation & $\begin{array}{l}\text { Helping others aligns with my personal values; we should strive to } \\
\text { improve ourselves; I value individualism and agency; lifelong learning; } \\
\text { being truthful is central to who I am }\end{array}$ \\
\hline
\end{tabular}

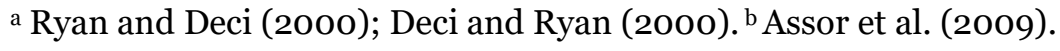

\section{Results}

During interviews, it was discovered that instructors in one section, teaching approximately a quarter of the first-year cohort, changed the project. While the other students' assignment was designed to maximize agency, these instructors assigned students a topic related to a future career and dictated how the final artifact was structured. In our research, 12 students were part of the high-agency group while four were in the cohort with limited agency. Although both projects met the definition of OER-enabled pedagogy, data are desegregated based on the amount of agency awarded to students.

Table 3 displays a summary of the regulatory processes identified. No student response was coded to intrinsic motivation; however, all participants displayed a variety of forms of extrinsic motivation, and all indicated a response indicative of either identified or integrated regulation at least once. Thus, all students could be classified as at least partially autonomously regulated (Vansteenkiste et al., 2018). 


\section{Table 3}

Number of Participants Demonstrating External Regulatory Processes

\begin{tabular}{|l|l|l|l|l|l|}
\hline & $\mathrm{n}$ & $\begin{array}{l}\text { External } \\
\text { regulation }\end{array}$ & $\begin{array}{l}\text { Introjected } \\
\text { regulation }\end{array}$ & $\begin{array}{l}\text { Identified } \\
\text { regulation }\end{array}$ & $\begin{array}{l}\text { Integrated } \\
\text { regulation }\end{array}$ \\
\hline High agency & 12 & $4(33 \%)$ & $11(91.6 \%)$ & $11(91.6 \%)$ & $5(41.6 \%)$ \\
\hline Limited agency & 4 & $4(100 \%)$ & $3(75 \%)$ & $4(100 \%)$ & $1(25 \%)$ \\
\hline Total & 16 & $8(50 \%)$ & $14(87.5 \%)$ & $15(93.8 \%)$ & $6(37.5 \%)$ \\
\hline
\end{tabular}

Of all the respondents, 50\% had a statement coded to external regulation, which was further subdivided into responses indicating pursuit of a reward or punishment avoidance (Ryan \& Deci, 2020). The most common external regulation subtype was motivation to gain a reward, although two students indicated motivation based on it being a requirement, and one, completing schoolwork to get a high-paying job (see Table 4).

Table 4

Prevalence of External Regulation in Participants

\begin{tabular}{|c|c|c|c|}
\hline \multirow[t]{2}{*}{ External regulation code } & High agency $(n=12)$ & Limited agency $(n=4)$ & Total $(n=16)$ \\
\hline & \multicolumn{3}{|c|}{$n(\%)$} \\
\hline Tangible reward & Grade-2 (16.7) & $\begin{array}{l}\text { Grade }-4(100)^{\mathrm{a}} \\
\text { Future earnings }-1(25)^{\mathrm{a}}\end{array}$ & $6(37.5)$ \\
\hline $\begin{array}{l}\text { Avoid a threat of } \\
\text { punishment }\end{array}$ & Required-2 (16.7) & $\mathrm{o}(\mathrm{o})$ & $2(12.5)$ \\
\hline Total & & & $8(50)$ \\
\hline
\end{tabular}

${ }^{\text {a }}$ One student indicated both grade and future earnings.

Introjected regulation was desegregated into an avoidance and approach subtype. In avoidance introjection, an individual attempts to avoid a negative outcome, such as shame or guilt. An individual in another approach subtype is motivated by an attempt to feel pride or increase one's view of self-worth (Assor et al., 
2009). Students were evenly split, with half reporting an avoidance or approach mentality (see Table 5). Most students in this study (87.5\%) showed evidence of being motivated through introjected regulation, with the majority either mentioning an avoidance or approach subtype, although a few individuals displayed both.

\section{Table 5}

Prevalence of Introjected Regulation in Participants

\begin{tabular}{|l|l|l|l|}
\hline \multirow{2}{*}{$\begin{array}{c}\text { Introjected } \\
\text { regulation subtype }\end{array}$} & \multicolumn{1}{|c|}{ High agency $(n=12)$} & \multicolumn{1}{|c|}{ Limited agency $(n=4)$} & \multicolumn{1}{|c|}{ Total $(n=16)$} \\
\cline { 2 - 4 } & \multicolumn{3}{|c|}{$n(\%)$} \\
\hline Approach & $7(58.3)$ & $2(50)$ & $9(56.3)^{\mathrm{a}}$ \\
\hline Avoidance & $7(58.3)$ & $2(50)$ & $9(56.3)^{\mathrm{a}}$ \\
\hline
\end{tabular}

a Respondents were able to indicate both approach and avoidance.

The most common extrinsic motivation regulator was identified regulation. Student responses related to four themes: pragmatic skill acquisition, aiding in the acquisition of skills by others, career advancement, and a general feeling that choice and personal interest are motivating. Results are displayed in Table 6. Most students (87.5\%) felt motivated to gain skills they saw as being useful. A majority of participants (56.3\%) indicated motivation to help others gain knowledge, while nearly a third were motivated by the ability to choose assignments they found interesting. Only a quarter of those interviewed mentioned the project as building skills related to a future career.

\section{Table 6}

Prevalence of Identified Regulation in Participants

\begin{tabular}{|l|l|l|l|}
\hline \multirow{2}{*}{$\begin{array}{c}\text { Identified regulation } \\
\text { themes }\end{array}$} & \multicolumn{1}{|c|}{ High agency $(n=12)$} & \multicolumn{1}{|c|}{$n(\%)$} & \multicolumn{1}{|c|}{ Total $(n=16)$} \\
\cline { 2 - 4 } & \multicolumn{3}{|c|}{} \\
\hline $\begin{array}{l}\text { Pragmatic skill } \\
\text { acquisition }\end{array}$ & $10(83.3)$ & $4(100)$ & $14(87.5)$ \\
\hline $\begin{array}{l}\text { Aid in others' skill } \\
\text { acquisition }\end{array}$ & $8(66.7)$ & $1(25)$ & $9(56.3)$ \\
\hline Career advancement & $2(16.7)$ & $2(50)$ & $4(25)$ \\
\hline
\end{tabular}




\begin{tabular}{|l|l|l|l|}
\hline $\begin{array}{l}\text { Choice and personal } \\
\text { interest motivate me }\end{array}$ & $4(33.3)$ & $1(25)$ & $5(31.3)$ \\
\hline
\end{tabular}

Relatively few students indicated integrated regulation. This is reasonable considering that reaching this level takes "considerable awareness, self-understanding, and maturity" (Vansteenkiste et al., 2018, p. 32). In integrated regulation, an individual performs a behavior not only because of its perceived value but due to its alignment with more deeply held values. As indicated in Table 7, the following values were evident in student responses: (a) helping others aligns with personal values, (b) we should strive to improve ourselves, (c) there is inherent value in individualism and agency, (d) we should be lifelong learners, and (e) truthfulness is central to the concept of self.

\section{Table 7}

Prevalence of Integrated Regulation in Participants

\begin{tabular}{|l|l|l|l|}
\hline \multicolumn{1}{|c|}{ Integrated regulation themes } & \multicolumn{1}{|c|}{$\begin{array}{c}\text { High agency } \\
(n=12)\end{array}$} & \multicolumn{1}{|c|}{$\begin{array}{c}\text { Limited agency } \\
(n=4)\end{array}$} & \multicolumn{1}{c|}{$\begin{array}{c}\text { Total } \\
(n=16)\end{array}$} \\
\cline { 2 - 5 } & \multicolumn{2}{|c|}{$n(\%)$} & $3(18.8)$ \\
\hline Helping others aligns with my personal values & $3(25)$ & $0(0)$ & $3(18.8)$ \\
\hline We should strive to improve ourselves & $2(16.7)$ & $1(25)$ & $1(6.3)$ \\
\hline I value individualism and agency & $1(8.3)$ & o (0) & $1(6.3)$ \\
\hline We should be lifelong learners & $0(0)$ & $1(25)$ & $1(6.3)$ \\
\hline Being truthful is central to who I am & $1(8.3)$ & o (0) & \\
\hline
\end{tabular}

\section{Discussion}

\section{Implications of Student SDT Characteristics}

\section{External Regulation}

This project was intended to provide various motivational elements, particularly identified and integrated regulation, as these result in more autonomously regulated learning and the most positive outcomes 
(Vallerand et al., 2008). The assignment, however, was graded, meaning external regulation existed. Vansteenkiste et al. (2018) state that students need not progress through SDT elements like stages. Thus, external regulation is not necessary as a first step to intrinsic motivation. They also state that no evidence suggests external pressure will lead to higher levels of integration.

While this study was not designed to assess this dynamic, evidence here suggests that students' view of the project changed over time from controlled to more autonomous motivation. For example, when asked about his view at the start of class, Student 11 indicated, "I thought that it was, you know, going to be a lot of work, but something I had to get done." Later during the same interview, the student stated, "We can change somebody's life or change their ... concept on the whole thing." Similarly, Student 9 indicated, "At first, I kind of thought it was like busy work ... I was like, this is just, they are trying to find something else to give us a grade on." But later in the interview, the same student said, "Uhm, yea just most that at first, and then I started doing it and it was kind of like, well it kind of makes you want to think about what you want to do a little bit more." When reflecting back on the project, both of these students initially indicated external regulation but by the end of class demonstrated higher levels of integration. This does not mean all extrinsically motivated behavior will be internalized, generally or with OER-enabled pedagogy. However, we did see evidence that some students were initially externally regulated but later displayed autonomous regulation.

\section{Introjected Regulation}

A central component of OER-enabled pedagogy is the creation of an NDA. This element had a significant impact on students, manifesting as introjected regulation. Students were split between those who saw this negatively (avoidance) and more positively (approach). In relation to a project being visible publicly, Student 1 stated,

Knowing that people are going to see it from all over the place, it makes you want to make it look nicer, have more accurate information stuff, you don't want to mess something up that potentially globally is going to be viewed ... It makes a difference when you know that someone is going to grade it and give it back to you, like it doesn't really matter that much, but if everyone is going to see it, definitely makes you want to put ... more work in to it.

On the other hand, Student 12 viewed publicity as a positive motivator:

The most interesting part of the project was the whole development of like, how are you going to put this out there? 'Cause at first, it's like OK, you make a project, throw it out there, done. But then it was like, so this is you, like, like you are labeling yourself with this project. This is a piece of you at UPIKE. This is your first step of showing people what you can do.

Although one of these students felt pressured out of concern for being embarrassed while the other saw the opportunity to establish themselves, neither of these responses indicate a greater likelihood of regulatory transfer and maintenance. While introjected avoidance motivation has a more negative impact than introjected approach motivation, both are less positively correlated with student engagement, well-being, and mastery or goal attainment than integrated regulation (Assor et al., 2009). 
Some degree of introjection is inherent in OER-enabled pedagogy in NDA creation. However, to facilitate a more autonomous regulatory pattern, neither external nor introjected regulation should constitute a student's dominant motivational process. This is particularly important as transfer and maintenance decrease when pressures associated with controlled regulation are removed (Deci \& Ryan, 1985), which occurs when students complete an assignment or class.

\section{Identified Regulation}

While controlled motivation (external and introjected regulation) were evident, autonomous forms of motivation (identified and integrated regulation) appeared more dominant. All but one participant had a statement coded to identified regulation, and six students demonstrated integrated regulation. Regarding identified regulation, students viewed the project as helping build skills they saw as valuable. Student 4 stated,

It actually helped a pretty good amount because, uh coming to college, I didn't really know how to study ... so I got a pretty good like, uh, group of information about how to study for certain classes because I went and asked all my teachers, and they tell me how to study for their class, and I asked some students who got good grades, and I talked to them and they told me how they studied, and it actually helped me quite a bit.

Other students saw the project as a way to help colleagues build skills. Thus, even if one does not find an activity enjoyable, it may be viewed as a worthy endeavor (Vansteenkiste et al., 2018). Considering that identified regulation has been correlated with positive student outcomes (Burton et al., 2006; Howard et al., 2020; Vallerand \& Bissonnette, 1992; Vallerand et al., 2008), the number of students indicating this is promising.

\section{Integrated and Intrinsic Regulation}

Relatively few individuals clearly connected the project to deeply held personal beliefs (integrated regulation). When present, the most evident value expressed was that we should help others and that we should continually improve ourselves. Other students had general views about the value of agency and freedom, as Student 12 did:

Normally when you get a project for science or something, somebody tells you what to do. It's like, I'm doing this for them, but seeing that I had the option to pick the topic that I wanted to do, it made me have, like, free will.

The small number of participants displaying integrated regulation is not surprising. Integrated regulation requires a significant amount of self-awareness, self-understanding, and maturity and may be more easily achieved by older individuals (Sheldon \& Kasser, 2001; Vansteenkiste et al., 2018). Here, 6 of 16 firstsemester students had responses suggesting motivation rooted in deeper personal values.

No individuals had responses coded to intrinsic motivation, defined as behaviors that are engaged in because of a person's inherent interest and enjoyment of the activity (Ryan \& Deci, 2020). While the 
students displaying integrated regulation demonstrated maturity, there was no indication that if external pressures were removed they would complete the project.

\section{Agency's Impact on Motivational Characteristics}

While generalizations on the role of agency cannot be drawn from this study alone, it, along with previous research, has implications for open educators. Autonomy is a basic psychological need in SDT that must be encouraged to foster development of intrinsic motivation. Instructors may support student autonomy by giving them choice in activities (Niemiec \& Ryan, 2009). Students report benefits of autonomy-supporting teachers over controlling instructors, including academics, motivation, engagement, and perseverance (Reeve, 2006).

All the individuals in the limited-agency group, but only 2 of 12 in the high-agency classes, mentioned motivation based on earning a grade. This dynamic existed even though the project constituted a larger part of the final grade for the high-agency cohort. One explanation is that when permitted, students chose a topic that fit their interests. When learners see the meaning, relevance, and value of an assignment, they are more likely to exhibit identified or integrated regulation (Vansteenkiste et al., 2018). This may be easier when students have agency. In relation to introjected regulation, it is not surprising that results for the groups were identical. A major source of introjected regulation in OER-enabled pedagogy is in creating an NDA. This dynamic existed regardless of the level of student agency.

It is encouraging that all but one of the research participants had a response coded to identified regulation. Although more research is warranted to determine if these findings persist, the largest difference between high- and limited-agency classrooms was the number of students who mentioned their project being useful to others (see Table 6). This is interesting as both groups completed projects with the understanding that it would be available to future students. If confirmed, the findings would align with past research suggesting that autonomy support better facilitates self-regulation and engagement in prosocial behaviors (Gagne, 2003). Greater choice in selecting assignment topics may help students see the value of their work in helping others.

Finally, a greater proportion of individuals in the high-agency group displayed integrated regulation. Integration relates to bringing a behavior into congruence with deeply held values. It is plausible that having agency allows someone to select a topic that aligns with their existing values. Those in the limited-agency group were assigned a project aimed at connecting behaviors to career goals. Coherence between career aspirations, interests, and values is believed to enhance integrated regulation (Vansteenkiste et al., 2018). Here, aligning the project to career aspirations did not increase integration over those free to select a topic. This may indicate an interplay between autonomy and competence. Provided with agency, a student may select a topic in which they feel more competent. A first-year student discussing a future career may feel less competent in achieving a lofty goal, however.

Although comparisons based on student agency here are exploratory, results point to a few important considerations. Primary among these is that while OER-enabled and open pedagogy are student-centered approaches, not all activities are equally effective in fostering motivation. The potential for growth in 
autonomy, competency, and relatedness may differ significantly. If educators wish students to move toward intrinsically motivated behaviors, care must be taken in how activities are designed.

\section{Practical Application}

OER-enabled pedagogy may invoke external and introjected regulation. However, when students are encouraged to consider value to self and to others, an increase in autonomous regulation may occur. Seraphin et al. (2019) note that the use of NDAs provides an opportunity for innovation, which may help students to see greater value to themselves and others.

As mentioned, not all OER-enabled pedagogy is motivationally equal. One example of common NDAs is student-generated test banks, where students write questions to be used in tests within the semester and in future courses. While this activity likely holds higher value than a disposable assignment, if the dominant source of student motivation is the possibility of scoring higher on a later exam, this activity may not facilitate the growth of autonomous motivation.

A second example is the high-agency and limited-agency forms of open pedagogy assessed here. We found differences in how students perceived motivation when they had a high degree of freedom. Similarly, Sheu (2020) highlights how students felt autonomy was desirable when they were allowed to choose between writing test questions (NDA) or a paper (disposable assignment). It seems likely that in both instances, had greater autonomy been given to students, this freedom would have increased the potential for identified and integrated regulation to develop. Faculty engaging in OER-enabled pedagogy should involve students directly in the assignment process from conception to completion (Sheu, 2020). A more revolutionary approach may be to transition to ungrading, making the grade itself secondary to learning (Stommel, 2014).

Finally, we should be cautious how we use concepts such as value and motivation and realize that not all forms of motivation are equally beneficial. While no form of motivation may be bad, past research indicates that identified regulation is most effective in enhancing student performance and perceived knowledge transferability (Burton et al., 2006; Howard et al., 2020; Wang et al., 2020), while more intrinsic forms are better for student psychosocial well-being (Burton et al., 2006; Howard et al., 2020). In addition, as evidenced in this research, students may experience different forms of motivational regulation simultaneously. Taking the test question NDA example, students who engage in this activity may find the assignment valuable. However, while perceived value may increase the likelihood of assignment completion, this may not foster more beneficial forms of motivation. Even students who report being motivated may not refer to forms that transcend an individual class.

\section{Limitations}

This research has several limitations. The study was conducted with students at one institution. It is unknown if results are transferable to other institutions and student groups. As stated previously, open pedagogy may be implemented differently. Results from assignments constructed another way may yield different results. Finally, while we believe interviews are an effective way to determine student motivation, data in this study are self-reported perceptions. 


\section{Conclusion}

Student interviews suggest that OER-enabled pedagogy holds promise to engage students and foster autonomously regulated motivation. Decades of research outline academic, social, and psychological benefits of being autonomously regulated as well as how this impacts transfer and maintenance. Our results indicate that even in the presence of external regulation, students experience greater levels of identified and integrated regulation when participating in OER-enabled pedagogy. Moreover, students initially motivated by grades may begin to see greater value to their effort. These are promising findings as recent research suggests that during the first year of college, autonomous regulation may decrease and controlled regulation increase (Henderlong Corpus et al., 2020). OER-enabled pedagogy may be a method for counteracting this trend.

To be most effective, OER-enabled pedagogy must be structured in a way that allows autonomy, competence, and relatedness. Assignments may align to this philosophy but emphasize controlled regulators. Additionally, while OER-enabled pedagogy holds the potential to disrupt hegemony, it may do so most effectively when aligned with the principles espoused by SDT. Finally, specifically addressing how OER-enabled pedagogy and SDT can be used to enhance student motivation in distributed learning environments may further the field's understanding of how delivery modality impacts student success.

Future research should examine the relationship between student motivation and the use of OER-enabled pedagogy, particularly as it relates to those of diverse backgrounds and the agency given to students. Research should also address the various ways this pedagogical approach is applied and how these strategies impact development of autonomously regulated behavior. 


\section{References}

Al Abri, M., \& Dabbagh, N. (2019). Testing the intervention of OER renewable assignments in a college course. Open Praxis, 11(2), 195-209. https://doi.org/10.5944/openpraxis.11.2.916

Alessi, E., Sapiro, B., Kahn, S., \& Craig, S. (2017). The first-year university experience for sexual minority students: A grounded theory exploration. Journal of LGBT Youth, 14(1), 71-92. https://doi.org/10.1080/19361653.2016.1256013

Allan, B. A., Duffy, R. D., \& Collisson, B. (2018). Helping others increases meaningful work: Evidence from three experiments. Journal of Counseling Psychology, 65(2), 155-165. https://doi.org/10.1037/couoooo228

Assor, A., Vansteenkiste, M., \& Kaplan, A. (2009). Identified versus introjected approach and introjected avoidance motivations in school and in sports: The limited benefits of self-worth strivings. Journal of Educational Psychology, 101, 482-497. https://doi.org/10.1037/ao014236

Bali, M., Cronin, C., \& Jhangiani, R. (2020). Framing open educational practices from a social justice perspective. Journal of Interactive Media in Education, 202O(1), 10. https://doi.org/10.5334/jime.565

Baran, E., \& AlZoubi, D. (2020). Affordances, challenges, and impact of open pedagogy: Examining students' voices. Distance Education, 41(2), 230-244. https://doi.org/10.1080/01587919.2020.1757409

Burton, K., Lydon, J., D’Alessandro, D., \& Koestner, R. (2006). The differential effects of intrinsic and identified motivation on wellbeing and performance: Prospective, experimental, and implicit approaches to self-determination theory. Journal of Personality and Social Psychology, 91, 750762. https://doi.org/10.1037/0022-3514.91.4.750

Charmaz, K. (2012). The power and potential of grounded theory. Medical Sociology Online, 6(3), 2-15. https://citeseerx.ist.psu.edu/viewdoc/download?doi=10.1.1.1062.8596\&rep=rep1\&type=pdf

Couros, A., \& Hildebrandt, K. (2016). Designing for open and social learning. In G. Veletsianos (Ed.), Emergence and innovation in digital learning: Foundations and applications (pp. 143-162). Athabasca University Press.

Creswell, J. (2007). Qualitative inquiry \& research design: Choosing among five approaches (2nd ed.). Sage.

Cronin, C., \& MacLaren, L. (2018). Conceptualising OEP: A review of theoretical and empirical literature in open educational practices. Open Praxis, 2, 127. https://doi.org/10.5944/openpraxis.10.2.825

Deci, E., \& Ryan, R. M. (1985). Intrinsic motivation and self-determination in human behavior. Plenum. 
Deci, E., \& Ryan, R. M. (2000). The "what" and "why" of goal pursuits: Human needs and the selfdetermination of behavior. Psychological Inquiry, 11, 227-268. https://doi.org/10.1207/S15327965PLI1104_01

Deci, E., \& Ryan, R. M. (2008). Facilitating optimal motivation and psychological well-being across life's domains. Canadian Psychology/Psychologie canadienne, 49(1), 14-23. https://doi.org/10.1037/0708-5591.49.1.14

Dermody, R. (2019). Open pedagogy for teaching structures. In C. Brause, P. L. Clouston, \& N. Darling (Eds.), Building technology educator's society: 2019 (art. 3). University of Massachusetts. https://doi.org/10.7275/s9xd-h436

DeRosa, R., \& Jhangiani, R. (n.d.). Open pedagogy. http://openpedagogy.org/open-pedagogy/

DeRosa, R., \& Robison, S. (2017). From OER to open pedagogy: Harnessing the power of open. In R. S. Jhangiani \& and R. Biswas-Diener (Eds.), Open: The philosophy and practices that are revolutionizing education and science (pp. 115-124). Ubiquity Press. https://doi.org/10.5334/bbc.i

Dewey, J. (2018, April 1). First year experience programs. 1-4. Salem Press.

Farzan, R., \& Kraut, R. (2013). Wikipedia classroom experiment: Bidirectional benefits of students' engagement in online production communities. CHI '13: Proceedings of the ACM Conference on Human Factors in Computing Systems (pp. 783-792). ACM Press. https://doi.org/doi:10.1145/2470654.2470765

Froiland, J., Oros, E., Smith, L., \& Hirchert, T. (2012). Intrinsic motivation to learn: The nexus between psychological health and academic success. Contemporary School Psychology, 16, 91-100. https://doi.org/10.1007/BF03340978

Gagne, M. (2003). The role of autonomy support and autonomy orientation in the engagement of prosocial behavior. Motivation and Emotion, 27, 199-223. https://doi.org/10.1023/A:1025007614869

Hanover Research. (2014). Strategies for improving student retention. https://www.hanoverresearch.com/media/strategies-for-improving-student-retention.pdf

Hegarty, B. (2015, July/August). Attributes of open pedagogy: A model for using open educational resources. Educational Technology, 3-14. https://www.scribd.com/doc/276569994/Attributesof-Open-Pedagogy-A-Model-for-Using-Open-Educational-Resources

Henderlong Corpus, J., Robinson, A., and Wormington, S. (2020). Trajectories of motivation and their academic correlates over the first year of college. Contemporary Educational Psychology, 63, 101907. https://doi.org/10.1016/j.cedpsych.2020.101907 
Hess, A. (2020, June 19). 7 ways the coronavirus pandemic could change college this fall and forever. CNBC. https://www.cnbc.com/2020/06/19/7-ways-coronavirus-pandemic-may-change-collegethis-fall-and-forever.html

Hilton, J., III, Wiley, D., Chaffee, R., Darrow, J., Guilmett, J., Harper, S., \& Hilton, B. (2019). Student perceptions of open pedagogy: An exploratory study. Open Praxis, 11(3), 275-288. https://doi.org/10.5944/openpraxis.11.3.973

Howard, J., Bureau, J., Guay, F., Chong, J., \& Ryan, R. (2020). Student motivation and associated outcomes: A meta-analysis from self-determination theory [Unpublished manuscript]. Perspectives on Psychological Science. https://doi.org/10.1177/1745691620966789

Inamorato dos Santos, A., Punie, Y., Castaño-Muñoz, J. (2016). EUR 27938-Opening up education: A support framework for higher education institutions. JRC Science for Policy Report. https://doi.org/10.2791/293408

Jenkins, J., Sánchez, L., Schraedley, M., Hannans, J., Navick, N., \& Young, J. (2020). Textbook broke: Textbook affordability as a social justice issue. Journal of Interactive Media in Education, 202O(1), 3. http://doi.org/10.5334/jime.549

Jhangiani, R. (2017). Ditching the "disposable assignment" in favor of open pedagogy. E-xcellence in Teaching Blog. http://teachpsych.org/E-xcellence-in-Teaching-Blog/4583103

Khandkar, S. (n.d.). Open coding. http://pages.cpsc.ucalgary.ca/ saul/wiki/uploads/CPSC681/opencoding.pdf

Lane, A. (2009). The impact of openness on bridging educational digital divides. The International Review of Research in Open and Distance Learning, $10(5)$. https://doi.org/10.19173/irrodl.v10i5.637

Lightweis, S. (2014). The challenges, persistence, and success of white, working-class, first-generation college students. College Student Journal, 48(3), 461-467. https://eric.ed.gov/?id=EJ1045347

Marsh, J. (2018, 27 April). What open education taught me. Open Pedagogy Notebook. http://openpedagogy.org/program-level/what-open-education-taught-me/

Mudhovozi, P. (2012). Social and academic adjustment of first-year university students. Journal of Social Sciences, 33(2), 251-259. https://doi.org/10.1080/09718923.2012.11893103

Niemiec, C. P., \& Ryan, R. M. (2009). Autonomy, competence, and relatedness in the classroom: Applying self-determination theory to educational practice. Theory and Research in Education, 7, 133-144. https://doi.org/10.1177/1477878509104318 
Pillay, A., \& Ngcobo, H. (2010). Sources of stress and support among rural-based first-year university students: An exploratory study. South African Journal of Psychology, 4O(3), 234-240. https://doi.org/10.1177/008124631004000302

Pintrich, P. (2003). A motivational science perspective on the role of student motivation in learning and teaching contexts. Journal of Educational Psychology, 95, 667-686. https://doi.org/10.1037/0022-0663.95.4.667

Plant, R., \& Ryan, R. (1985). Intrinsic motivation and the effects of self-consciousness, self-awareness, and ego-involvement: An investigation of internally controlling styles. Journal of Personality, 53, 435-449. https://doi.org/10.1111/j.1467-6494.1985.tboo375.x

Polikoff, M., Silver, D., \& Korn, S. (2020, August 4). What's the likely impact of COVID-19 on higher ed? Inside Higher Education. https://www.insidehighered.com/views/2020/08/04/analysis-datanational-survey-impact-pandemic-higher-ed-opinion

Pulliam, N., \& Gonzalez, C. (2018). Success or fraud? Exploring the impacts of the impostor phenomenon among high achieving racial/ethnic minority and first-generation college students. Journal of Access, Retention, \& Inclusion in Higher Education, 33-45. https://www.wcupa.edu/universityCollege/asp/documents/ADP\%20Journal-2018First\%20Edition-corrected.pdf $\#$ page $=39$

Reeve, J. (2006). Teachers as facilitators: What autonomy-supportive teachers do and why their students benefit. Elementary School Journal, 106, 225-236. https://doi.org/10.1086/501484

Reeve, J. (2012). A self-determination theory perspective on student engagement. In S. L. Christenson, A. L. Reschly, \& C. Wylie (Eds.), Handbook of research on student engagement (pp. 149-172). Springer. https://doi.org/10.1007/978-1-4614-2018-7 7

Reynolds, A., \& Weigand, M. (2010). The relationships among academic attitudes, psychological attitudes, and the first-semester academic achievement of first-year college students. Journal of Student Affairs Research and Practice, 47(2), 175-195. https://doi.org/10.2202/1949-6605.6004

Robbins, S., Lauver, K., Le, H., Davis, D., Langley, R., \& Carlstrom, A. (2004). Do psychosocial and study skill factors predict college outcomes? A meta-analysis. Psychological Bulletin, 13O(2), 261-288. https://doi.org/10.1037/0033-2909.130.2.261

Roberts, J., \& Styron, R. (2010). Student satisfaction and persistence: Factors vital to student retention. Research in Higher Education Journal, 1-18. https://www.aabri.com/manuscripts/o9321.pdf

Ryan, R. (1982). Control and information in the intrapersonal sphere: An extension of cognitive evaluation theory. Journal of Personality and Social Psychology, 43, 450-461. https://doi.org/10.1037/0022-3514.43.3.450 
Ryan, R., \& Deci, E. (2000). Self-determination theory and the facilitation of intrinsic motivation, social development, and well-being. American Psychologist, 55, 68-78. https://doi.org/10.1037/0003o66X.55.1.68

Ryan, R., \& Deci, E. (2020). Intrinsic and extrinsic motivation from a self-determination theory perspective: Definitions, theory, practices, and future directions. Contemporary Educational Psychology, 61, 101860. https://doi.org/10.1016/j.cedpsych.2020.101860

Seifert, T. (2004). Understanding student motivation. Educational Research, 46(2), 137-149. https://doi.org/10.1080/0013188042000222421

Seraphin, S., Grizzell, J., Kerr-German, A., Perkins, M., Grzanka, P., \& Hardin, E. (2019). A conceptual framework for non-disposable assignments: Inspiring implementation, innovation, and research. Psychology Learning and Teaching, 18(1), 84-97. $\underline{\text { https://doi.org/10.1177/1475725718811711 }}$

Sheldon, K., \& Kasser, T. (2001). Getting older, getting better: Personal strivings and psychological maturity across the life span. Developmental Psychology, 37, 491-501. https://doi.org/10.1037/0012-1649.37.4.491

Sheu, F. (2020). Learner perceptions of open pedagogy in a psychology course: A case study on instructional design with open educational resources. In M. Y. Zhou (Ed.), Open educational resources (OER) pedagogy and practice (pp. 67-90). IGI Global.

Skjott Linneberg, M., \& Korsgaard, S. (2019). Coding qualitative data: A synthesis guiding the novice. Qualitative Research Journal, 19(3), 259-270. https://doi.org/10.1108/QRJ-12-2018-0012

Stommel, J. (2014, November 17). Critical digital pedagogy: A definition. Hybrid Pedagogy. https://hybridpedagogy.org/critical-digital-pedagogy-definition/

Stommel, J. (2015, May 28). Open door classroom [SlideShare slides]. https://www.slideshare.net/jessestommel/open-door-classroom

Tillinghast, B. (2020). Developing an open educational resource and exploring OER-enabled pedagogy in higher education. IAFOR Journal of Education: Technology in Education, 8(2). https://doi.org/10.22492/ije.8.2.09

Vallerand, R., \& Bissonnette, R. (1992). Intrinsic, extrinsic, and amotivational styles as predictors of behavior: A prospective study. Journal of Personality, 6o, 599-620. https://doi.org/10.1111/j.1467-6494.1992.tboog22.x

Vallerand, R. J., Pelletier, L. G., \& Koestner, R. (2008). Reflections on self-determination theory. Canadian Psychology, 49, 257-262. https://doi.org/10.1111/j.1467-6494.1992.tbo0922.x

Vansteenkiste, M., Aelterman, N., De Muynck, G.-J., Haerens, L., Patall, E., \& Reeve, J. (2018). Fostering personal meaning and self-relevance: A self-determination theory perspective on internalization. 
Journal of Experimental Education, 86, 30-49.

https://doi.org/10.1080/00220973.2017.1381067

Wang, C., Zhang, Y., Moss, J. D., Bonem, E. M., \& Levesque-Bristol, C. (2020). Multilevel factors affecting college students' perceived knowledge transferability: From the perspective of self-determination theory. Research in Higher Education, 61, 1002-1026. https://doi.org/10.1007/s11162-02009592-x

Wiley, D. (n.d.). Defining the "open" in open content and open educational resources. Open Content. http://opencontent.org/definition/

Wiley, D. (2013, October 21). What is open pedagogy? Open Content Blog. https://opencontent.org/blog/archives/2975

Wiley, D., \& Hilton, J. (2018). Defining OER-enabled pedagogy. International Review of Research in Open \& Distance Learning, 19(4), 133-147. https://doi.org/10.19173/irrodl.v19i4.3601

Wiley, D., Webb, A., Weston, S., \& Tonks, D. (2017). A preliminary exploration of the relationships between student-created OER, sustainability, and students' success. The International Review of Research in Open and Distributed Learning, 18(4). https://doi.org/10.19173/irrodl.v18i4.3022

Woolfolk, A. (2019). Educational psychology (14th ed). Pearson.

\section{Athabasca} University

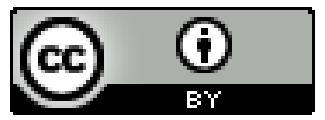

